Int. J. Morphol.,

38(4):815-819, 2020

\title{
Sex Prediction by Analysis of the Morphological Characteristics of Macerated Skulls
}

\author{
Predicción Sexual Mediante Análisis de las Características Morfológicas de Cráneos Macerados
}

\author{
Nilton Alves ${ }^{1,2,3}$; Naira Figueiredo Deana ${ }^{4}$; Javier González ${ }^{3}$ Pamela Hernández ${ }^{3}$ \& Francisco Ceballos ${ }^{3}$
}

ALVES, N.; DEANA, N. F.; GONZÁLEZ, J.; HERNÁNDEZ, P. \& CEBALLOS, F. Sex prediction by analysis of the morphological characteristics of macerated skulls.Int. J. Morphol., 38(4):815-819, 2020.

SUMMARY: The skull is a reliable structure for determining the sex of an adult individual; it is generally resistant in adverse conditions, allowing it to be used for the analysis of sexual dimorphism. In the present study we analysed 10 non-metric characteristics of skulls of Brazilian adult individuals in order to: Determine the strength of association between sex and the morphological characteristics of the skull, the morphological characteristic(s) with greatest diagnostic influence for sex, and analyse whether the morphological characteristics of the skull predict sex. The study included 179 macerated skulls of Brazilian adults, (69 female, 110 male). The sex of all the skulls included was identified. The investigators were calibrated prior to analysis and all the evaluations were carried out under blinding. Pearson's Chi-squared test was used. The sensitivity and specificity were analysed and a ROC curve was constructed. Binary logistic regression was carried out. The SPSS v.22 software was used, with a significance threshold of $5 \%$. All the characteristics analysed presented statistically significant differences $(p<0.05)$. The frontal profile, the superciliary arch and the glabella presented the greatest sensitivity, best balance between sensitivity and specificity and greatest area under curve. The regression model with the frontal profile, superciliary arch and mastoid process was significant $[\mathrm{X} 2(2)=115,728$ $\mathrm{p}=0.000, \mathrm{R}^{2}$ Negelkerke $=0.657$ ], and presented correct sex classification in $90 \%$ of cases (Males: $87.4 \%$; Females: $83.1 \%$ ). In unknown individuals for whom the skull is present, non-metric analysis of the frontal profile, superciliary arch, mastoid process and glabella can be used as instruments for sex identification.

KEY WORDS: Sex determination; Morphological characteristics; Macerated skulls; Brazilians.

\section{INTRODUCTION}

Determining sex from bones or bone fragments is necessary in cases when the remains are in a state which makes identification of an unknown individual difficult (Krishan et al., 2016). Sex is usually determined by a metrical approach, based on the size of a structure, or a non-metrical approach based on the presence or degree of expression of dimorphic sexual characteristics (Lewis \& Garvin, 2016). According to the literature, the pelvis presents the greatest reliability for determining sex, and the skull is the next best indicator (Bass, 2005). The skull presents bone structures with a high degree of sexual dimorphism, allowing accuracy of up to $94 \%$ (Krogman \& Iscan, 1986); the mastoid process and the glabella are the morphological characteristics which allow sex to be determined with the greatest accuracy
(Walker, 2008). It should be noted that the accuracy of a characteristic will depend on the degree of dimorphism shown for the reference collection (McDowell et al., 2012); we must therefore consider that a determined characteristic may present a greater or lesser degree of dimorphism depending on the population of origin.

In the present study we analysed 10 non-metric characteristics of skulls of Brazilian adult individuals in order to: determine the strength of association between sex and the morphological characteristics of the skull; determine the morphological characteristic(s) with greatest diagnostic power for sex; and finally, analyse whether the morphological characteristics of the skull predict sex.

\footnotetext{
${ }^{1}$ Center of Excellence in Morphological and Surgical Studies (CEMyQ), Faculty of Medicine, Universidad de La Frontera, Temuco, Chile. ORCID ID: 0000-0001-7878-1810

${ }^{2}$ Applied Morphology Research Center (CIMA), Faculty of Dentistry, Universidad de La Frontera, Temuco, Chile.

${ }^{3}$ Faculty of Dentistry, Universidad de La Frontera, Temuco, Chile.

${ }^{4}$ Center for Research in Epidemiology, Economics and Oral Public Health (CIEESPO), Faculty of Dentistry, Universidad de La Frontera, Temuco, Chile.
} 


\section{MATERIAL AND METHOD}

The study included 179 macerated skulls of Brazilian adults of both sexes, of whom 69 were female and 110 male. They belonged to the Department of Morphology and Genetics, UNIFESP (Brazil). Only skulls with information on sex and nationality were included. Skulls with fractures or malformations were excluded. Researchers were calibrated before carrying out the analysis; they were blinded during the evaluations.

The morphological characteristics were analysed following the classification of Walrath et al. (2004), in a modified version (Table I).

Statistical analysis. The association between sex and the variables analysed was evaluated by Pearson's chi-squared test, and the strength of association between sex and the morphological characteristics was assessed by the Phi coefficient (f). The strength of association was interpreted as suggested by Cohen (1988), being classified as small (0.10), medium (0.30), large (0.50) or very large $(\geq 0.70)$. The sensitivity and specificity were analysed for each variable and a ROC curve was constructed to analyse the best diagnostic test. A hierarchical binary logistic regression was carried out to determine whether the morphological characteristics of the skull can predict sex. The SPSS v.22 software was used, with a significance threshold of $5 \%$.

\section{RESULTS}

Strength of association between sex and the morphological characteristics of the skull. All the characteristics analysed presented statistically significant differences $(\mathrm{p}<0.05)$. In the strength of association analysis, the frontal profile and the superciliary arch presented the highest degrees of association, both classified as having a large strength of association. All the other characteristics analysed presented a strength of association smaller than 0.500 , and were therefore classified as having a medium strength of association (Table II).

Analysis of the sensitivity, specificity and ROC curve. The frontal profile, the superciliary arch and the glabella presented the greatest sensitivity and the best balance between sensitivity and specificity; the shape of the orbit presented the least sensitivity (Table III). The frontal profile was the variable presenting the greatest area under curve (AUC), followed by the superciliary arch and the glabella; this result showed that these three characteristics presented the greatest power for diagnosing sex. The frontal and parietal eminences, the shape of the orbit, and the zygomatic process of the temporal bone were the characteristics with the smallest AUC; they presented a value very close to 0.500 , showing their low power for diagnosing sex (Table III, Fig. 1).

Binary logistic regression. The correct sex classification obtained from each morphological characteristic analysed is described in Table IV. All the characteristics presented a statistically significant value, except the shape of the orbit and the zygomatic process of the temporal bone. The frontal profile was the only characteristic which presented a combined percentage higher than $80 \%$ for sex classification, with a prognosis for sex identification of $44.4 \%$. It was the morphological characteristic with the greatest ability to predict sex. The superciliary arch, the glabella and the frontal eminence presented correct

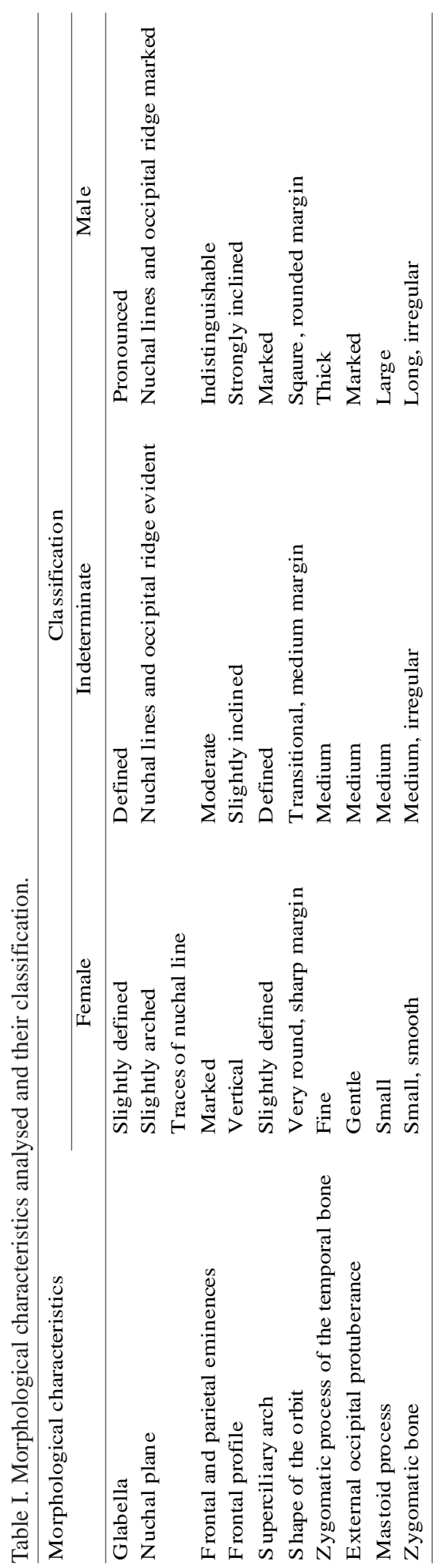


sex classification higher than $70 \%$. The other characteristics analysed presented a percentage lower than $70 \%$, i.e. a lower rate of correct sex classification. Better sex classification was obtained for males than females with all the characteristics analysed except the superciliary arch.

Table II. Degree of association between sex and morphological characteristics.

\begin{tabular}{lcc}
\hline Morphological characteristics & \multicolumn{2}{c}{$\boldsymbol{X}^{2}$} \\
& p-value & Phi _ \\
\hline Frontal profile & 0.000 & 0.602 \\
Superciliary arch & 0.000 & 0.588 \\
Glabella & 0.000 & 0.490 \\
Zygomatic bone & 0.000 & 0.335 \\
External occipital protuberance & 0.000 & 0.326 \\
Mastoid process & 0.003 & 0.275 \\
Nuchal plane & 0.005 & 0.268 \\
Frontal and parietal eminences & 0.013 & 0.246 \\
Zygomatic process of the temporal bone & 0.041 & 0.214 \\
Shape of the orbit & 0.041 & 0.188 \\
\hline
\end{tabular}

In the binary logistic regression analysis, the model containing the frontal profile, superciliary arch and mastoid process was significant $\left[\mathrm{X} 2(2)=115,728 \mathrm{p}=0.000, \mathrm{R}^{2}\right.$ Negelkerke $=0.657]$. The percentage of correct sex classification using these three morphological characteristics was $87.4 \%$, with $83.1 \%$ for females and $90.0 \%$ for males.

The frontal profile $(\mathrm{OR}=0.089$; CI $95 \%=$ 0.034-0.236), the superciliary arch $(\mathrm{OR}=0.093$; CI $95 \%=0.017-0.499)$ and the mastoid process $(\mathrm{OR}=0.223$; CI $95 \%=0.069-0.720)$ were significant predictors; the other characteristics analysed in the present study were not significant predictors and were excluded from the binary logistic regression model.

Table III. Sensitivity, specificity and Area Under Curve (AUC) for the morphological characteristics of the skull.

\begin{tabular}{lccc}
\hline Morphological characteristics & Sensitivity & Specificity & AUC \\
\hline Frontal profile & $84.5 \%$ & $74.6 \%$ & 0.809 \\
Superciliary arch & $92.6 \%$ & $43.0 \%$ & 0.792 \\
Glabella & $89.1 \%$ & $50.0 \%$ & 0.756 \\
External occipital protuberance & $78.0 \%$ & $52.1 \%$ & 0.672 \\
Mastoid process & $78.5 \%$ & $56.4 \%$ & 0.653 \\
Zygomatic bone & $75.8 \%$ & $54.4 \%$ & 0.652 \\
Nuchal plane & $73.7 \%$ & $43.4 \%$ & 0.632 \\
Zygomatic process of the temporal bone & $66.7 \%$ & $38.2 \%$ & 0.578 \\
Frontal and parietal eminences & $69.1 \%$ & $44.7 \%$ & 0.557 \\
Shape of the orbit & $65.4 \%$ & $56.5 \%$ & 0.541 \\
\hline
\end{tabular}

Table IV. Correct sex classification.

\begin{tabular}{lccccc}
\hline Morphological characteristics & $\mathrm{R}^{2} \mathrm{~N}_{\text {agelkerke }}$ & \multicolumn{3}{c}{ Correct sex classification } & \multirow{2}{*}{$\mathrm{p}$-value } \\
\cline { 3 - 5 } & & Female & Male & Total & 0.000 \\
Frontal profile & 0.444 & $74.6 \%$ & $84.7 \%$ & $80.9 \%$ & $75.8 \%$ \\
S uperciliary arch & 0.438 & $94 \%$ & $72.1 \%$ & $73.7 \%$ & 0.000 \\
Glabella & 0.300 & $76.5 \%$ & $94.5 \%$ & $71.3 \%$ & 0.000 \\
Frontal and parietal eminences & 0.369 & $33.8 \%$ & $91.8 \%$ & $66.1 \%$ & 0.000 \\
External occipital protuberance & 0.148 & $23.9 \%$ & $72.1 \%$ & $65.7 \%$ & 0.000 \\
Zygomatic bone & 0.118 & $55.2 \%$ & $78.2 \%$ & $63.8 \%$ & 0.002 \\
Mastoid process & 0.098 & $40.3 \%$ & $98.2 \%$ & $60.5 \%$ & 0.004 \\
Nuchal plane & 0.014 & $0.0 \%$ & $91.0 \%$ & $64.4 \%$ & 0.087 \\
Shape of the orbit & 0.037 & $19.7 \%$ & $100 \%$ & $62.4 \%$ & 0.064 \\
Zygomatic process of the temporal & 0.026 & $0.0 \%$ & &
\end{tabular}

\section{DISCUSSION}

In some situations, for example when bodies are exposed to heat, distortion of the soft tissues occurs, hindering sex determination (Gonçalves et al., 2013); it is necessary to identify the sex from bones or bone fragments which have resisted heat or other disaster situations. The skull is a reliable structure for determining the sex of an 


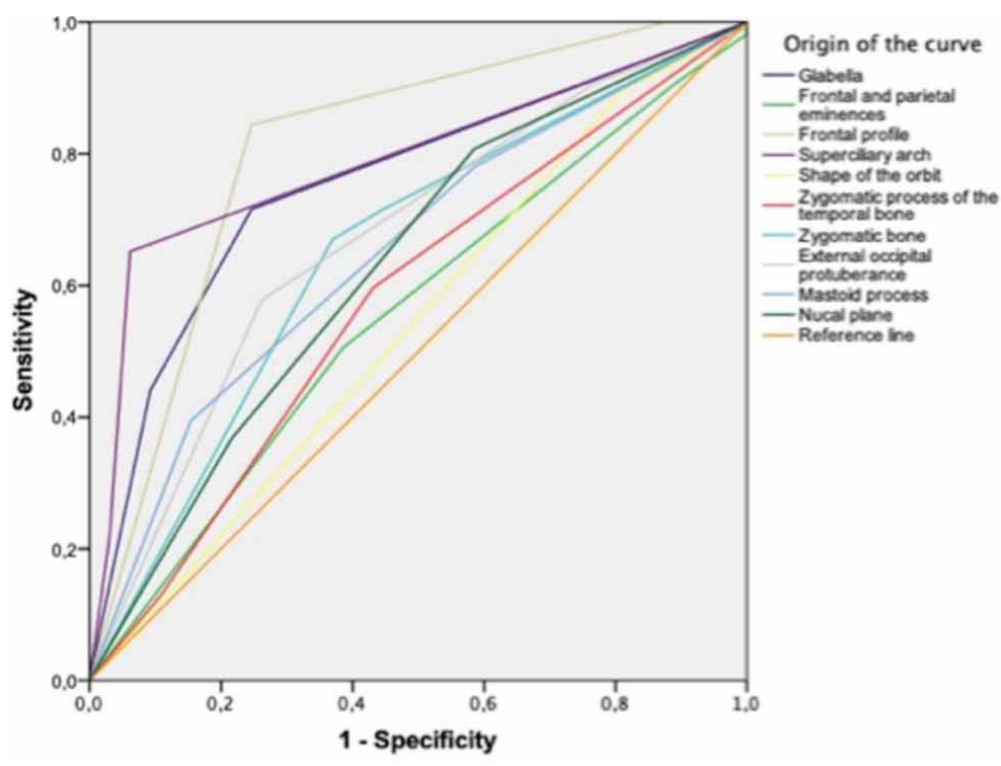

et al. (2009) observed that the frontal profile presented an accuracy of $80.14 \%$, with a higher percentage of correct diagnoses for females $(84.94 \%)$ than males $(77.65 \%)$; this corroborates the findings of our study, showing that the frontal profile is a reliable indicator for determining sex. In the same study, Suazo et $a l$, found an accuracy of $78.79 \%$ for sex diagnosis using the superciliary arch, with correct diagnosis of a larger number of male skulls $(79.21 \%)$ than female $(77.89 \%)$. In another study, Ramsthaler et al. (2010) reported $85 \%$ accuracy for this characteristic, indicating that it presented great sexual dimorphism. In our study, the superciliary arch proved to be a reliable indicator for determining sex, with combined correct sex classification of $75.8 \%$
Fig. 1. ROC curve for morphological characteristics of the skull.

adult individual (Best et al., 2018); it is generally resistant to adverse conditions, allowing it to be used for the analysis of sexual dimorphism. The degree of sexual dimorphism differs between populations due to environmental factors; however, regardless of the population, males tend to have stronger muscles and more robust joints (Bigoni et al., 2010). Previous studies in Brazilian individuals by our research team have shown some skull structures that can be used as predictors of sex in the identification of unknown individuals from bone remains. Some examples are metric analysis of the height of the piriform aperture (Alves et al., 2019), the bigonial breadth, mandibular ramus height and bicondilar breadth (Alves \& Deana, 2019); and non-metric analysis of the mandible by evaluation of the shape of the chin (Deana \& Alves, 2017).

The advantage of analysis based on non-metric features is that it can be used to analyse bone fragments; furthermore it does not require special equipment, which makes evaluation easier. The principal disadvantage is that it is a subjective criterion, and it is important for the evaluator to have suitable experience with the evaluation method used to identify sex (Lewis \& Garvin).

In this investigation we analysed 10 morphological characteristics of the skull, making 3 different comparisons: we analysed the strength of association between morphological characteristics and sex; we determined the morphological characteristics with the greatest power of sex diagnosis; and we analysed the morphological characteristics. In the three analyses carried out, the frontal profile was the variable which showed the greatest reliability for sex diagnosis, followed by the superciliary arch. Suazo and a higher percentage of male skulls correctly diagnosed than female skulls.

Analysis by hierarchical binary logistic regression in our study showed correct sex classification of $90 \%(87.4 \%$ for males and $83.1 \%$ for females) using 3 characteristics: frontal profile, superciliary arch and mastoid process. The results reported by Garvin et al. (2014) differ from ours, showing that the glabella and the mastoid process are the most reliable features for determining differences in sex. In another study, an analysis of skulls from the Pretoria Bone Collection, Krüger et al. (2015) found similar results to those of Garvin et al. These authors reported $80 \%$ accuracy ( $94 \%$ in males and $67 \%$ in females) in sex determination using the glabella and the mastoid process; however the highest accuracy (84\% combined, $92 \%$ in males and $76 \%$ in females) was found using the 3 characteristics: glabella, mastoid process and chin (Krüger et al.). In a study with CT scans, Ramsthaler et al., obtained correct classification of $96 \%$, with the highest accuracy rates given by the supraorbital ridge, the glabella, the mastoid process and the supraorbital margins. Williams \& Rogers (2006) showed that the mastoid process presents great sexual dimorphism, with accuracy of up to $92.0 \%$. Suazo et al. indicate that the mastoid process was the most accurate indicator (84.75\%), with good balance between sensitivity and specificity $(92.09 \% / 80.00 \%)$. In our study the mastoid process presented a significant association with sex, being classified with minor strength (Phi $\mathrm{f}=0.275$ ), a sensitivity of $78 \%$, a specificity of $56.4 \%$ and AUC $=0.653$. Although it did not present a better performance than other diagnostic tests, this characteristic presented correct sex classification of $63.8 \%$; it was a significant characteristic in the hierarchical binary logistic regression model. 
Non-metric analysis of the glabella has been reported in previous studies to be a good sex identifier when used with other morphological characteristics of the skull (Garvin et al.; Krüger et al.; Ramsthaler et al.), or as a single identifier, with up to $96.7 \%$ correct sex classification (Lewis \& Garvin). In our study, the glabella was excluded from the binary logistic regression analysis of the model because it lacked statistical significance; however in the other two statistical analyses applied, this variable proved to be a good diagnostic power for sex $(A U C=0.756)$; it was also significantly associated with sex with a medium strength of association (Phi $\mathrm{f}=0.490)$. This corroborates previous studies showing that the glabella is a reliable indicator for identifying sex (Garvin et al.; Krüger et al.; Lewis \& Garvin; Ramsthaler et al.).

In conclusion, all morphological characteristics of the skulls analysed, presented sexual dimorphism, however the frontal profile and the superciliary arch presented the highest degree of association with sex and the greatest power of sex diagnosis from skull samples. Sex determination using 3 morphological characteristics presented $90 \%$ correct sex classification and $65.7 \%$ sex prediction. In unknown individuals for whom the skull is present, non-metric analysis of the frontal profile, superciliary arch, mastoid process and glabella may be used for sex identification.

ALVES, N.; DEANA, N. F.; GONZÁLEZ, J.; HERNÁNDEZ, P. \& CEBALLOS, F. Predicción sexual mediante análisis de las características morfológicas de cráneos macerados. Int. J. Morphol., 38(4):815$819,2020$.

RESUMEN: El cráneo es una estructura confiable para la determinación sexual de un individuo adulto y suele ser resistente en condiciones adversas, por lo que puede ser utilizado para el análisis del dimorfismo sexual. En el presente estudio analizamos 10 características no métricas de cráneos de individuos brasileños adultos a fin de determinar la fuerza de asociación entre el sexo y características morfológicas del cráneo; determinar la(s) característica(s) morfológica(s) con mejor poder para diagnosticar el sexo; y analizar si las características morfológicas del cráneo son previsoras del sexo. Fueron incluidos 179 cráneos macerados de brasileños adultos, $(69$ femeninos, 110 masculinos). Todos los cráneos incluidos presentaban identificación de sexo. Los investigadores fueron previamente calibrados y todas las evaluaciones fueron realizadas de forma ciega. Se utilizó la prueba de Chicuadrado de Pearson. Se analizó la sensibilidad y especificidad y se construyó una curva ROC. Se realizó regresión logística binaria. Se utilizó el software SPSS v.22, considerando umbral de significación de $5 \%$. Todas las características analizadas presentaron diferencias estadísticas significativas $(\mathrm{p}<0,05)$. El perfil frontal, el arco superciliar y la glabela fueron las características que presentaron mayor sensibilidad, mejor equilibrio sensibilidad/especificidad y mayor area under curve. El modelo de regresión con el perfil frontal, arco superciliar y proceso mastoides fue significativo $\left[\mathrm{X} 2(2)=115,728 \mathrm{p}=0.000, \mathrm{R}^{2}\right.$ Negelkerke $=0,657]$, y presentó una clasificación sexual correcta de 90 \% (Males; 87,4 \%; Females: 83,1 \%). En individuos desconocidos en los cuales esté presente el cráneo, el análisis no-métrico del perfil fron- tal, del arco superciliar, del proceso mastoides y de la glabela pueden ser utilizados como herramienta para identificación sexual.

PALABRAS CLAVE: Determinación sexual; Características morfológicas; Cráneos macerados; Brasileños.

\section{REFERENCES}

Alves, N. \& Deana, N. F. Sex prediction from metrical analysis of macerated mandibles of Brazilian adults. Int. J. Morphol.; 37(4):1375-81, 2019.

Alves, N.; Deana, N. F.; Ceballos, F.; Hernández, P. \& González, J. Sex prediction by metric and non-metric analysis of the hard palate and the pyriform aperture. Folia Morphol. (Warsz.), 78(1):137-44, 2019.

Bass, W. Human Osteology. A Laboratory and Field Manual. $5^{\text {th }}$ ed. Columbia, Missouri Archaeological Society, 2005.

Best, K. C.; Garvin, H. M. \& Cabo, L. L. An investigation into the relationship between human cranial and pelvic sexual dimorphism. J. Forensic Sci., 63(4):990-1000, 2018

Bigoni, L.; Velemínská, J. \& Bruzek, J. Three-dimensional geometric morphometric analysis of cranio-facial sexual dimorphism in a Central European sample of known sex. Homo, 61(1):16-32, 2010.

Deana, N. F. \& Alves, N. Nonmetrical sexual dimorphism in mandibles of Brazilian individuals. Biomed. Res. (India), 28(9):4233-8, 2017.

Garvin, H. M.; Sholts, S. B. \& Mosca, L. A. Sexual dimorphism in human cranial trait scores: effects of population, age, and body size. Am. J. Phys. Anthropol., 154(2):259-69, 2014.

Gonçalves, D.; Thompson, T. J. \& Cunha, E. Osteometric sex determination of burned human skeletal remains. J. Forensic Leg. Med., 20(7):906-11, 2013.

Krishan, K.; Chatterjee, P. M.; Kanchan, T.; Kaur, S.; Baryah, N. \& Singh, R. $\mathrm{K}$. A review of sex estimation techniques during examination of skeletal remains in forensic anthropology casework. Forensic Sci. Int, 261:165.e1$8,2016$.

Krogman, W. \& Iscan, M. The Human Skeleton in Forensic Medicine. Springfield (Illinois), Charles C. Thomas, 1986.

Krüger, G. C.; L’Abbé, E. N.; Stull, K. E. \& Kenyhercz, M. W. Sexual dimorphism in cranial morphology among modern South Africans. Int. J. Legal Med., 129(4):869-75, 2015.

Lewis, C. J. \& Garvin, H. M. Reliability of the Walker cranial nonmetric method and implications for sex estimation. J. Forensic Sci., 61(3):743-51, 2016.

McDowell, J. L.; L'Abbé, E. N. \& Kenyhercz, M. W. Nasal aperture shape evaluation between black and white South Africans. Forensic Sci. Int., 222(1-3):397.e1-6, 2012.

Ramsthaler, F.; Kettner, M.; Gehl, A. \& Verhoff, M. A. Digital forensic osteology: morphological sexing of skeletal remains using volume-rendered cranial CT scans. Forensic Sci. Int.; 195(1-3):148-52, 2010.

Suazo, G. I. C.; Zavando, M. D. A. \& Smith, R. L. Performance evaluation as a diagnostic test for traditional methods for forensic identification of sex. Int. J. Morphol., 27(2):381-6, 2009.

Walker, P. L. Sexing skulls using discriminant function analysis of visually assessed traits. Am. J. Phys. Anthropol., 136(1):39-50, 2008.

Walrath, D. E.; Turner, P. \& Bruzek, J. Reliability test of the visual assessment of cranial traits for sex determination. Am. J. Phys. Anthropol., 125(2):1327,2004.

Corresponding author:

Naira Figueiredo Deana

Universidad de La Frontera

Faculty of Dentistry

Avda. 1145 Francisco Salazar

PO BOX 54-D

Temuco -CHILE

Received: 08-01-2020

Accepted: 20-02-2020

Email: n.figueiredo01@ufromail.cl 